\title{
The Establishment of Functional Play Behaviors in Children with Autism: Implications for School Inclusion
}

\section{Daniel Carvalho de Matos ${ }^{1,2}$, Pollianna Galvão Soares de Matos ${ }^{1,2}$, Creuziana Xavier de Araújo3, Camila Gonçalves Ribeiro4, Eliane Ribeiro Magalhães de Sousa Fortes de Melo $^{3}$}

${ }^{1}$ The Assessment, Research and Intervention Laboratory for Autism Spectrum Disorder at CEUMA University, São Luís, Brazil

${ }^{2}$ Postgraduate Program in Psychology of the Federal University of Maranhão, São Luís, Brazil

${ }^{3}$ CEUMA University, São Luís, Brazil

${ }^{4}$ Federal University of Maranhão, São Luís, Brazil

Email:dcmatos23@hotmail.com,polliannagalvao@yahoo.com.br

How to cite this paper: de Matos, D. C., de Matos, P. G. S., de Araújo, C. X., Ribeiro, C. G., \& de Melo, E. R. M. S. F. (2018). The Establishment of Functional Play Behaviors in Children with Autism: Implications for School Inclusion. Creative Education, 9, 1910-1930.

https://doi.org/10.4236/ce.2018.913140

Received: July 21, 2018

Accepted: October 15, 2018

Published: October 18, 2018

Copyright ( 92018 by authors and Scientific Research Publishing Inc. This work is licensed under the Creative Commons Attribution International License (CC BY 4.0).

http://creativecommons.org/licenses/by/4.0/

\begin{abstract}
Research on evidence-based methodologies is conducted to expand skills of children with autism. Among the skills, which might be considered important for development, the literature emphasizes functional play. In many children with Autism Spectrum Disorder (ASD), the repertoire related to play is impaired and specialized treatment may address the issue by designing individualized procedures based on one-to-one interactions. Discrete trial teaching may help establishing such repertoire in a structured setting and generalization goals must be delineated to increase the likelihood with which the learned skills will emerge in new environments, such as the classroom, the home and other natural contexts. Thus, it is important that skills be shown in places where other people participate. Principles from Educational Psychology are also relevant in the advisory process to professionals related, for example, to school settings in order to favor inclusion of children with ASD to school routine and the relationship with peers. People related to these educational environments should become knowledgeable of evidence-based procedures in order to increase, with their help, generalization of previously established skills in more structured contexts. This paper assessed the efficacy of a structured intervention with functional play activities in three 4-year-old children with autism or suspect. A binder with pictures depicting actions with the components of each of four or two toy sets was used as resource to orient the target-responses of the study. Correct responses, under the control of pictures, produced access to tokens exchangeable for preferred items. Errors were corrected. Errorless performance occurred for all children with res-
\end{abstract}


ponses under the control of pictures for all and generalization with two toy sets for one. The results extended those from the previous literature and, even though the generalization to other environments such as school was not directly measured, the implications of the research to inclusion practices in the school context and development of verbal behavior were discussed.

\section{Keywords}

Autism, Educational Psychology, Functional Play, School Inclusion, Verbal Behavior

\section{Introduction}

In a scenario where atypical human development has been a target for political actions to build less excluding social spaces, the development of research related to Psychology commitment in current inclusive educational contexts is necessary. Although expanded, the educational policies in Brazil have been filled with controversies when they conduct to practical unfolding at school context. The Law of Guidelines and Bases of National Education (Brazil, 1996), the National Policy on Special Education in the Perspective of School Inclusion (Brazil, 2008) and, specially, the National Policy for the Protection of the Rights of Persons with Autism Spectrum Disorder (Brazil, 2012) and the National Plan for the Rights of Persons with Disabilities (Brazil, 2015) present wide advocacy on the equity of formal education at all levels of education.

In this context, school psychologists have been called upon to support individuals with an autism spectrum disorder in both mainstream and special education setting, especially in support to teacher's performance (Gomes \& Souza, 2011). This professional certainly is required to provide services to students, their parents and educators. For this reason, it is important that school psychologists have a good understanding of autism and evidence-based approaches to work with atypical students in the process of school inclusion (Otero, Fina, Barker, \& Skues, 2017).

The current conception in school inclusion sustains the idea of educational practices, which involve the personalized attention and respect to individual characteristics of the people (Dazzani, 2010; Galvão \& Beckman, 2016; Gomes \& Souza, 2011; Lemos, Salomão, Braz-Aquino, \& Agripino-Ramos, 2016; Martins \& Monteiro, 2017). Specially, during the beginning years of schooling process, competences related to social interactions are the focus of pedagogical intervention and children with autism, usually, present a lack in the development of relevant behaviors at school when compared to their typically developing peers. Sanini, Sifuentes and Bosa (2013) emphasize the need to identify factors that favor the interaction of children with autism and other children at school, even though not all researchers from the field of developmental psychology agree on a specific kind of play activity that would be the most effective in promoting such 
interactions.

Despite the controversy, theorists of developmental psychology argue that children with or without phenotypic changes in development should experience mediations with an emphasis on the establishment of play skills in moments of interaction to promote the expansion of important psychological processes in infancy, such as imagination, abstraction, generalization (Martins \& Monteiro, 2017), which are indeed important to acquisition and development of language.

Stichter, Tillman and Jimerson (2016) highlight that there is a considerable number of researches on assessment, identification and support services to children with autism. However, as Matos and Matos (2017) point out, more investigations on this theme at school are in need to support the actions of teachers in promoting inclusion practices. This paper defends the idea that designing specialized interventions aimed at children with autism may be beneficial for them and can be used to expand the means of learning and development at school, especially with the mediation of psychoeducational strategies used among peers such as play activities.

Studies in different perspectives of Psychology have investigated themes related to play and social interactions of children with autism, such as Akers, Higbee, Pollard, Pellegrino and Gerencser (2016), Kasari, Chang and Patterson (2013), Martins (2009), Martins and Monteiro (2017), Passerino and Santarosa (2007), Phillips and Vollmer (2012), Orrú (2006), Wong and Kasari (2012). These authors conducted researches with distinct proposals of analysis, but all of which converge to the theme of social relationship established with autistic individuals through play.

Play skills are considered important for child development for several reasons. They may increase verbal interactions between different children and the opportunities to learn new behaviors especially because other people may become models. Children with autism frequently show impairments in several domains and play skills are usually affected. Sundberg (2008) states that, when children are having fun through play, it is very likely that they will verbalize more spontaneously. Typically developing children commonly manipulate several toys, one at a time and consistently moves from one to another after few seconds have elapsed. This author contends that increasing both frequency and variability in play behaviors should be one important intervention goal.

Psychology comprises different perspectives to ameliorate deficits of children with autism (Lemos et al., 2016). Behavioral principles derive from Skinner's contributions through operant conditioning and he is also acknowledged for the proposal of technology of teaching which respects the pace of the student to learn new skills (Skinner, 1953/2003; Skinner, 1968/1972). These and other principles may be very useful to guide interventions in School Psychology in the process of inclusion, interventions which should address domains such as functional play, which is, besides other repertoires, important for inclusion in the school context and others (Otero et al., 2017; Stichter, Tillman \& Jimerson, 
2016).

Specialized interventions must address different component skills related to play: 1) functional with the appropriate manipulation of toys according to the function; 2) manipulation of toys composed of several little parts, like Mr. Potato Head and colored blocks (the interventionist will be also addressing abilities such as fine motor skills, visual perception, imitation and problem solving); 3) symbolic play (this one is frequently the most impaired type of play skill in children with autism) (Sanini, Sifuentes, \& Bosa, 2013; Kasari et al., 2013; Sundberg, 2008), which is present in situations where a typical child, for example, manipulates a spoon pretending it is a drumstick or moves a block the way he/she would do with a little car. However, children with autism frequently lack this ability. According to Kasari et al. and Martins and Monteiro (2017), many young children with autism usually exhibit functional play skills more frequently than symbolic play. In fact, the author states that functional play may be established later in the development of autistic children, but also says that symbolic play maybe will never emerge or the frequency will be low. Demonstrations of play skills later in natural environment may be discrete, especially symbolic play.

Interventions to develop both functional and symbolic play should focus on teaching variability in playing with both real toys (functional play) and common items from every day (symbolic play) (Sundberg, 2008). The gains may be limited, because they depend on the process of child symbolization related to play according to the learning history. Kasari et al. (2013) stated that, if it is expected that play be fun, creative and spontaneous, many children with autism may not in fact be demonstrating play skills the way the typical child does, especially considering the case of symbolic play. They also say that, even though these children may be able to learn how to perform relevant response topographies through behavioral strategies, the activities may not in fact be fun for them, and spontaneity may be compromised. According to Kasari et al., other abilities may be key components for the development of play skills. One case is related to joint attention, which is the ability to coordinate the attention between an item and the presence of another person. About this theme Wong and Kasari (2012) compared the performances of 27 autistic children in play activities and joint attention with the case of 28 children with other learning disabilities in special education classrooms. The autistic children showed lower frequencies regarding these skills.

Functional play skills are more likely when they are fun for the children. This is an important condition for their spontaneous demonstration. Drawing a child's attention to the task may be a challenging endeavor, considering that the child may show no interest in toys or other activities that the typical child considers fun. If the mediator invests in a good rapport, it may be expected that adherence to the activities will improve and that leisure activities and toys will eventually become more motivating. In some cases, evidence based practices may include teaching sequences of behaviors through prompting strategies with 
visual stimuli to guide the behaviors to be performed.

Akers et al. (2016) investigated the efficacy of a procedure, which used a photographic activity schedule with the purpose of establishing play skills in an independent manner by three children with autism from 4 to 5 years old in a playground. An activity schedule consists in a range of pictures that function as cues to the completion of a sequence of activities. It represents several steps or actions to be performed under the control of pictures and it is a very useful pedagogical resource at school context. The mentioned children, instead of playing appropriately during unstructured moments, engaged in stereotypic behaviors. For intervention, they showed prerequisite skills, consisting in matching to sample responses and basic listener behaviors.

The playground contained a wall rock, two sets of ladders, a slide and other materials. There were 16 tasks, like driving a tricycle in a specific route. Each schedule was organized in a small binder with several pages. A different picture was attached to each page representing a specific action or sequence of actions. First, the participants learned how to pair the pictures to the places where the toys were and go to these places. During baseline, the children were instructed to go play and no prompts were given. The intervention condition with the activity schedule present involved the delivery of physical prompts, which were gradually faded as well as the distance between experimenter and child, for the completion of the activities. Independent responses produced access to tokens, which were later exchanged for preferred items. Later, a condition with new activities was programmed with the same format as the previous one and a follow up probe was conducted after two weeks. As result, there were improvements, considering the number of activities concluded and they were maintained during follow up. However, the activity schedule always needed to be present for correct responding, otherwise performance dropped to baseline level.

Phillips and Vollmer (2012) developed a procedure to teach chains of play behavior to three 4 years old children with speech-language delay (one of them is autistic). They manipulated visual prompts for engagement with several toys with independence, conducting assessments to see if the pictures would be established as the controlling variables of play behavior. Four toy sets (like a barn with horse, cow, tractor, etc.) served to perform different response sequences. Pictures representing actions to be performed with the components of the toys were used during the conditions of the study. The pictures portrayed different actions and groups were organized, so that different sequences of actions could be evoked for a same toy set. Each picture from a set was attached to a page of a binder with several pages. One final page contained the phrase "All done!" to signal the end of a sequence. The primary dependent variable was the percentage of steps completed by the participants according to the pictures. Data collection occurred in a school in a place close to the children's classrooms, which were equipped with a kitchen, three tables, chairs and toys. The experimenter sat by the child's side and the child sat towards a wall. 
The study conditions were: 1) assessment of prerequisite skills (receptive identification of objects, visual-visual arbitrary matching of pictures to their objects and following instructions consisting in simple actions with objects); 2) baseline which consisted of the participants receiving an instruction to demonstrate the actions depicted by the pictures for each one of several toy sets. No prompts and differential consequences for correct and incorrect responses were provided; 3) teaching of page turning for all children; 4) instruction test condition to assess if the general instruction consisting in telling the children to do what was on the pictures would be sufficient to evoke responding under the control of the pictures; 5) training condition with differential reinforcement (praise) for correct responses and prompting procedures for incorrect ones. Until five prompt levels could be presented always in the same order by the experimenter (general instruction to do what was on the picture; specific instruction to perform the action; pointing to relevant objects while presenting the specific instruction; response modeling while presenting the specific instruction; physical guidance); 6) probing new sequences of steps after conclusion of the previous condition (pictures in new order); 7) single instruction training in case the original teaching procedure was not successful (pictures presented one at a time on the first page of the binder. All other pages were removed).

The procedure established correct response sequences for all and there was some generalization to novel toy sets after learning with one to three sets. Data suggested establishment of stimulus control by pictures. The arrangement of pictures to assess responding with them in a different order for a same set, after achieving criteria during training the original order, also served as a measure of control by pictures. The experimental design (multiple baseline) and the learning of page turning by the participants also may have demonstrated the same control.

Researches like those conducted by Phillips and Vollmer (2012) and Akers et al. (2016) describe examples of procedures, which scientifically proved to be effective in establishing complex chains of functional play behaviors in children with learning disabilities. In both studies it was argued that the participants lacked the behavior repertoires, related to functional play, before the implementation of their teaching procedures, which combined the use of prompts, including visual and audio prompts, fading and reinforcement of independent performance. Functional play behaviors involve, for example, the emission of actions with toys the way they are supposed to be manipulated (Sundberg, 2008). The typical child in general does not need special interventions to learn this repertoire. Nevertheless, many children with autism frequently do not develop this type of skill spontaneously and play usually comprises sequences of complex chained behaviors, which represent a challenge for many learners. The procedures by the mentioned authors were effective in children who apparently were unable to learn chained functional play behaviors incidentally. The studies also suggest that the procedures may have implications for the development of 
functional play in new environments and before other people, besides those who were involved in the teaching process.

It is worth to say that many behaviors, which are important for the lives of individuals in general, are emitted in chain. The typical learner develops many repertoires consisting of complex chain of behaviors, which refer to skills people show everyday, regarding, for example, daily living skills and vocational tasks, besides the aforementioned functional play skills, which typically developing children show with time, but the same frequently is not true for those with developmental delays. In fact, it is known that the learning of different type of behavior chains may be a serious endeavor for many individuals with ASD and other disabilities. Several studies in the literature regarding evidence-based practices addressed this issue with participants at different ages (Phillips \& Vollmer, 2012; Pierce \& Shreibman, 1994; Wacker \& Berg, 1983; Wacker, Berg, Berrie, \& Swatta, 1985). In general, in these studies, task analysis converts a given activity into several steps that may be taught as behavior chains (Partington, 2006).

In a behavior chain, the outcome of each step of the chain serves the function of a discriminative stimulus for the response of the next step and as a conditioned reinforcer for the response from the previous step (Skinner, 1953). The use of prompting strategies and contingencies of reinforcement represent a way of establishing the complex repertoires mentioned. Sometimes, the training needs to be intense, but prompts must be faded out in order to produce changes in stimulus control. That means that the goal with fading out the prompts gradually is the establishment of responding under the control of the relevant stimuli of the behavior chain solely. The prompts may be physical and the fading process involves reducing the use of them in a manner that allows the learner to perform a given task more independently. The visual cues, however, may be used as an alternative to physical prompts, that require the teacher being in closer proximity to the learner and the research by Akers et al. (2016) suggested that the visual cues used with the purpose of teaching activities related to play behaviors in a playground possibly favored independent performances by the children of the research and with the experimenter at a certain distance. The procedure by Phillips and Vollmer (2012), who used visual cues as well and assessed their possible role as controlling variables of functional play behaviors, also allows for the discussion about the relevance of visual stimuli in establishing performance free from the close proximity of someone, and this is important for the development of independence.

Considering the efficacy demonstrated by the procedures from the previous literature in establishing play skills, consisting of complex behavior chains in children with autism who frequently lack them, through the use of visual prompts and schedules of reinforcement, further investigation about the possible generality of the results with more participants should be addressed. The present research involved a design similar to the one developed by Phillips and Vollmer (2012). In their study, data suggested that the conducted procedures produced 
chains of play behavior by the participants under the control of pictures portraying behavior chains. It would be interesting to check if their design could produce similar results for Brazilian children with ASD, who are part of a different culture in comparison to those from the previous study. One may believe or suppose that, although many children with ASD who live abroad benefit from procedures regarding the teaching of behavior chains in contexts such as classrooms through photographic activity schedules, the same is not true for many children with ASD who live in Brazil. One important aspect regarding the participants of the current research is that they had no previous experience with the learning of skills through photographic activity schedules in contexts such as the school, when compared to the participants from previous studies, who were used to learning through this methodology before the researches, in which they were part, were conducted. In this sense, regarding the current research, it is important to assess if the procedures similar to those by Phillips and Vollmer produce similar or different results in children with no previous experience with activity schedules in the school context. At last, the research also had the purpose to conduct a discussion on the implications of evidence-based procedures as possible important tools for school inclusion of children with ASD.

\section{Method}

\subsection{Participants}

Three 4-year-old Brazilian children participated. They all showed language delays, but only two had been diagnosed with autism. The remaining one was suspected of autism by associated characteristics. They were all level two learners according to the milestones protocol from the Verbal Behavior Milestones Assessment and Placement Program (Sundberg, 2008).

According to this protocol, all participants were able to make requests of desirable items, such as edibles and preferred toys, through phrases, which consisted of three word utterances (e.g. "I want cake"). They were able to label approximately 100 non-verbal stimuli, such as objects and pictures and to describe some two-component verb-noun combinations (e.g. when a teacher showed a picture portraying a woman reading a book, the children said "reading book"). All participants could receptively identify over 200 non-verbal stimuli consisting in objects and pictures when their names were spoken to them and were able to follow many verbal instructions describing simple actions with and without objects. They all demonstrated a generalized matching-to-sample repertoire, regarding the process of pairing objects and pictures to identical models and they were advancing in the process of pairing similar stimuli (e.g. pairing two different models of cars). They all demonstrated a generalized repertoire of motor imitation and imitation with objects and were advancing in the development of fine motor skills through modeling. They were developing a repertoire of identi-

fying receptively non-verbal stimuli such as pictures and objects through verbal 
instructions, which specified function, feature and class of the stimuli.

Regarding the ability of verbal interaction by answering arbitrary verbal stimuli, it was in the process of being developed for all participants. They were able to complete several different fill-in-the-blank phrases (e.g. the teacher said "you sleep in a..." and the child completed "bed"), but, for them, "what, who and where questions" were harder and were under development. About the skills related to independent play, it is important to mention that, although all of the participants were able to demonstrate several simple actions with toys through modeling, they in general did not demonstrate consistent functional play involving several actions in sequence, like assembling parts of Mr. Potato Head or of a hamburger toy set. This was important in order to ensure that the participants could not demonstrate behaviors, which were defined as targets for the current research.

\subsection{Instruments: Experimental Environment and Materials}

Sessions occurred in a clinic situated in a private university. They were conducted individually, and the teaching area contained a table, chairs and materials like toys and pictures portraying actions with them. Each of several pictures represented a different action and was enclosed inside a laminated page from a binder. A participant sat on one of the chairs and an experimenter sat on the other one near the child. The manipulated toys consisted of sets with multiple component pieces like the ones used in the research by Phillips and Vollmer (2012). A different action or step could be performed with each piece. If one of the toy sets consisted of a Mr. Potato Head and components, one possible step, for example, would consist in inserting one of the arms into its corresponding hole.

In this research, for one of the participants (P1), four toy sets were used and they consisted of: 1) Mr. Potato Head with nine steps to be performed; 2) snack with eight steps to prepare a hamburger; 3) snack with nine steps to prepare a fruit salad; 4) a blender with eight steps to prepare a smoothie. For the remaining participants (P2 and P3), only two sets, corresponding to the first and second sets used for P1, were employed. The parents of two participants (P2 and P3) were unable to buy toy sets other than the ones mentioned. For all participants, considering each toy set, the number of steps corresponded to the number of pages in the binder with a picture representing a different step on each page. The pictures were independent from each other, so their order in the binder could be changed. Like in previous research by Phillips and Vollmer (2012), the participants could learn to complete behavior sequences under the control of pictorial instructions. The final page in the binder contained the printed word "all done!". A digital camera was used to take all pictures employed during the experiment and each of them depicted a close-up of a person completing a step in a way that only the hands and relevant materials for the step were shown. Figure 1 presents two examples of steps to be performed. 

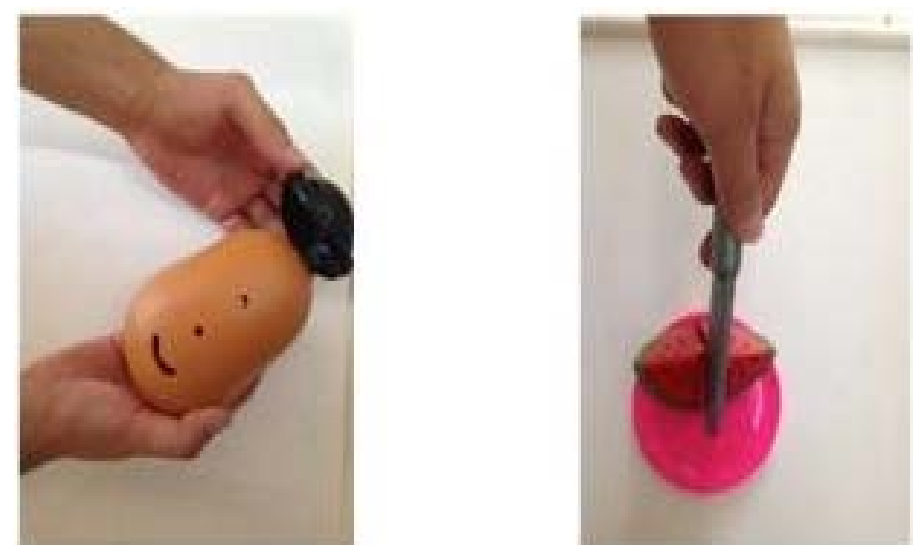

Figure 1. Example of pictures representing a step of two of the toy sets used for the participants.

\subsection{Data Collection Procedures}

Sessions were conducted two or three times per week. The primary dependent variable was the percentage of correct responses consisting in completing the steps for each toy set during assessment and training blocks of trials. A binder always depicted a sequence of pictures representing the steps and correct performance was established as long as each participant completed the steps in the correct order shown. Correct and incorrect responses were recorded on data sheets. On a successful trial, the experimenter recorded a + sign on a column corresponding to a block of trials. Incorrect response (or no response) was recorded as - sign. Incorrect responses were defined as 1) the child completing an action with an object that did not correspond to the one depicted on the picture; 2) the child performing a response out of the sequence; 3 ) the child performing an action that did not correspond to any of the steps. During approximately $50 \%$ of assessment and intervention sessions, data were also collected by a second observer to establish an interobserver agreement (IOA). This was calculated by dividing the number of agreements by the number of agreements plus disagreements and multiplying by 100 to obtain a percentage. The mean IOA was $97 \%$ for all participants.

\subsection{Intervention and Testing Procedures}

For participation in the study, the presence of some skills was assessed. All participants could match objects and pictures to their samples (visual-visual identity matching) and objects to their pictures and vice-versa (visual-visual arbitrary matching). They also could select pictures and objects upon hearing their names.

Baseline. The components of each toy set were separately placed in front of each participant on the table as well as the binder with the pictures in a given order. After this, the experimenter gave an instruction to engage with the materials (e.g., "show me how you prepare a hamburger"). Prompts were not given during this condition. Engagement with the materials was praised, but no other differential consequences were provided. 
Page turning. The manipulation of the binder was taught to each participant after stability during baseline was established for at least one toy set. The binder was presented without any pictures and the children were verbally oriented to open the binder and turn each page inside it. Physical prompts were applied when necessary and were gradually faded to establish an independent performance. When the final page, containing the written words "all done!", was reached, the experimenter gave an echoic prompt and gradually faded it so the children could verbalize the words independently. When all participants were able to open the binder, turn all pages and say the words on the last page without any help, this condition was discontinued.

Instruction test. This condition was established to verify if the participants were able to perform the steps depicted on the pictures, but demanded a generic instruction to attend to the pictures in order to perform the actions ("do what is in the picture"). If that were the case for a given participant, his/her participation would be discontinued. However, in general, none of the participants performed significantly during this condition and it was terminated.

Intervention. An important difference, when compared to baseline, was that different levels of prompts were administered if necessary to establish correct performance. A hierarchy of prompts was programmed and applied as follows: 1) from $5 \mathrm{~s}$ to $10 \mathrm{~s}$ after presentation of the materials and initial instruction to engage with them or after the completion of a step, no prompts were given so the participant could demonstrate a correct response; 2) if there was no demonstration of correct performance, the first prompt level consisted in presenting a vocal prompt to do what the picture showed; 3 ) if not enough, a specific vocal prompt to do the action depicted on the picture was given (e.g., "put lettuce on bread"); if not enough, besides giving the specific vocal prompt, the experimenter pointed to the relevant components for the completion of the step; 4) if necessary, the experimenter performed the action himself and verbalized the specific vocal prompt; 5) finally, if no previous prompt was successful, the experimenter guided the child physically to perform the action.

Prompts during the intervention were administered, when necessary, from the time each child had to open the binder until all of the pages were turned and their steps concluded. For each step, all participants had from $5 \mathrm{~s}$ to $10 \mathrm{~s}$ to emit a correct response. Whenever a given child completed a step without the experimenter's aid, verbal praise was given and a small token was attached to a platform. Accumulated tokens could be exchanged for access to preferred toys and edibles at the end of a session, which lasted approximately $40 \mathrm{~min}$ and could involve several blocks of trials. The criteria to finish the intervention condition consisted in two consecutive blocks of trials with $100 \%$ correct responses free from any prompts.

Probing a new sequence of steps. After finishing a given toy set during the previous condition, a probe with a new sequence of steps was conducted as a stimulus control test. The procedure was identical to the one used during baseline. 
If the participant showed $100 \%$ consecutive responses in at least two consecutive blocks of trials, it would be assumed that the responses were being emitted under the control of the pictorial stimuli. If this was not met, the new sequence would also be trained, but that was never necessary for any participant considering all of the manipulated toy sets.

\subsection{Data Analysis Procedures}

To ensure that targeted behaviors (chains of play behaviors in the presence of pictures) were a function of the intervention, the experimental design consisted of a multiple-probe design across different toy sets for each participant. First, baseline levels were established with different toy sets and pictures portraying actions with them for each of the three participants; then, after stability was demonstrated, the procedures regarding intervention were placed for one of the toy sets for each participant. While intervention condition was in course for a single toy set, baseline data collection continued in several occasions for the remaining ones (three more for P1 and one more for P2 and P3). After an arbitrary criterion was reached for the first toy set, indicating improvement on performance, the intervention began for another set as well. This was a characteristic of the design to ensure experimental control by the independent variable. In the case of the current research, considering the first and second toy sets for all participants, improvements on performance were demonstrated only when the intervention took place. Data were analyzed regarding this kind of single case research design in accordance with the literature, which legitimates it (Horner \& Baer, 1978). For P1 with whom four toy sets were used, the intervention was not necessary for third and fourth toy sets and improvement possibly occurred as a generalization effect from the training with the previous toy sets.

\subsection{Ethical Procedures}

An informed consent form was signed by the parents of the children, for their participation and the research was approved by an ethics committee in research with humans (authorization No. 1.189.331) humans from Ceuma University, São Luís-MA.

\section{Results}

Figures 2-4 represent data for participants 1, 2 and 3, respectively, during the following conditions: first baseline, instruction test, intervention and second baseline with the pictures arranged in a new order.

As it can be seen in Figure 2, P1 did not demonstrate any correct performance during baseline for the first toy set (Mr. Potato Head). During the instruction test condition, the verbal instruction to do what was on the picture was also not enough to evoke correct responses in two blocks of trials tested. During intervention, correct performance was progressively established across several blocks and the condition was terminated after the sixth block. After baseline 


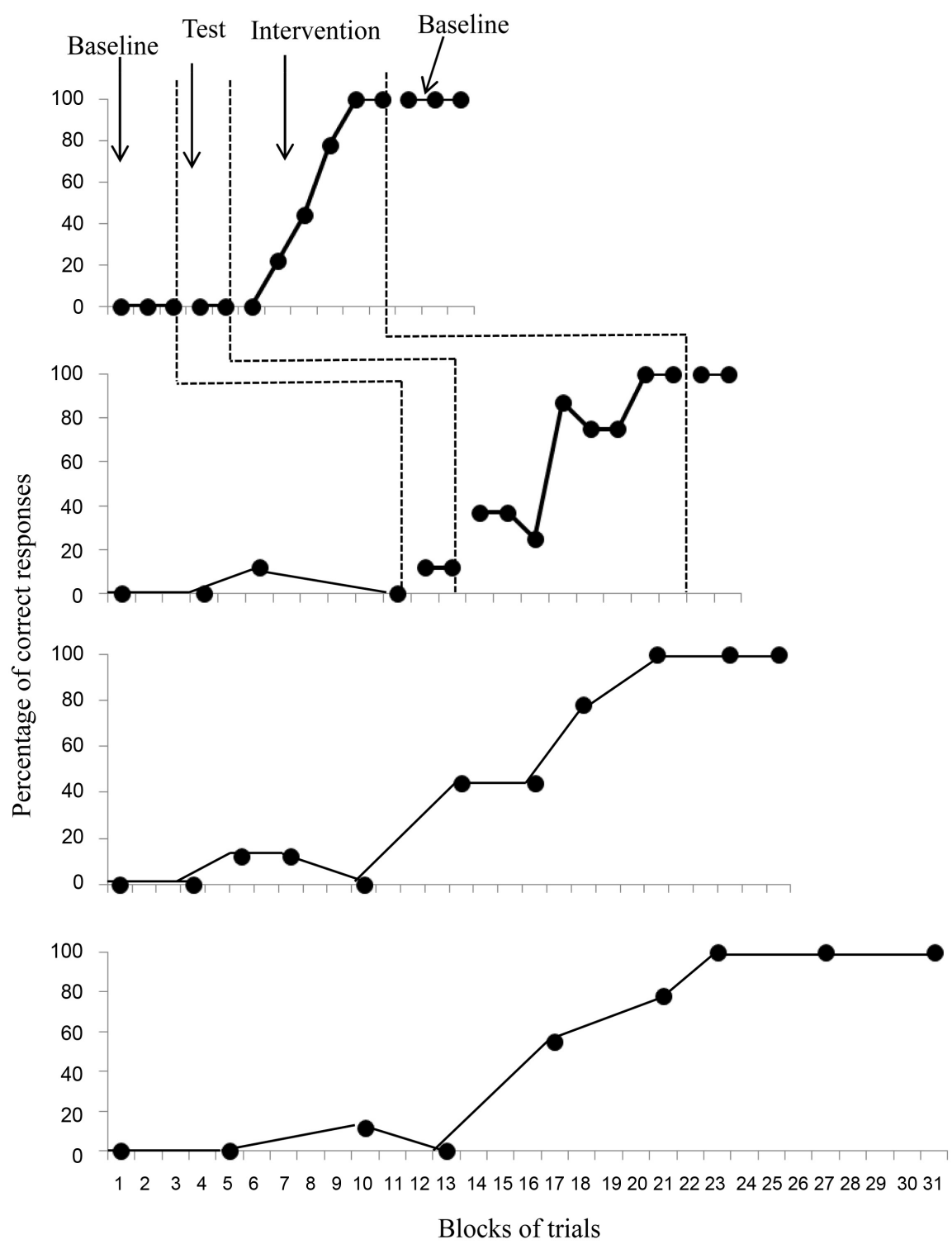

Figure 2. Percentage of steps completed correctly per block of trials for P1. Panels 1 and 2 represent data for the first (Mr. Potato Head), second (hamburger), third (fruit salad) and fourth toy (smoothie) sets.

condition was re-established with the pictures in a different order for the set, a performance free from errors was maintained in three consecutive blocks. For the second toy set (hamburger), correct performance was low across the tested blocks of trials and, during the instruction test condition, the performance was near zero in two consecutive blocks. During intervention, correct responses were also progressively established like in the case of the previous toy set and the condition was terminated after eight blocks of trials. Plus, during the return to baseline condition, no errors were demonstrated during two consecutive blocks to assess performance with the pictures arranged in a new order. In the case of both third (fruit salad) and fourth (smoothie) toy sets, correct performance was progressively established across several blocks of trials during baseline condition 


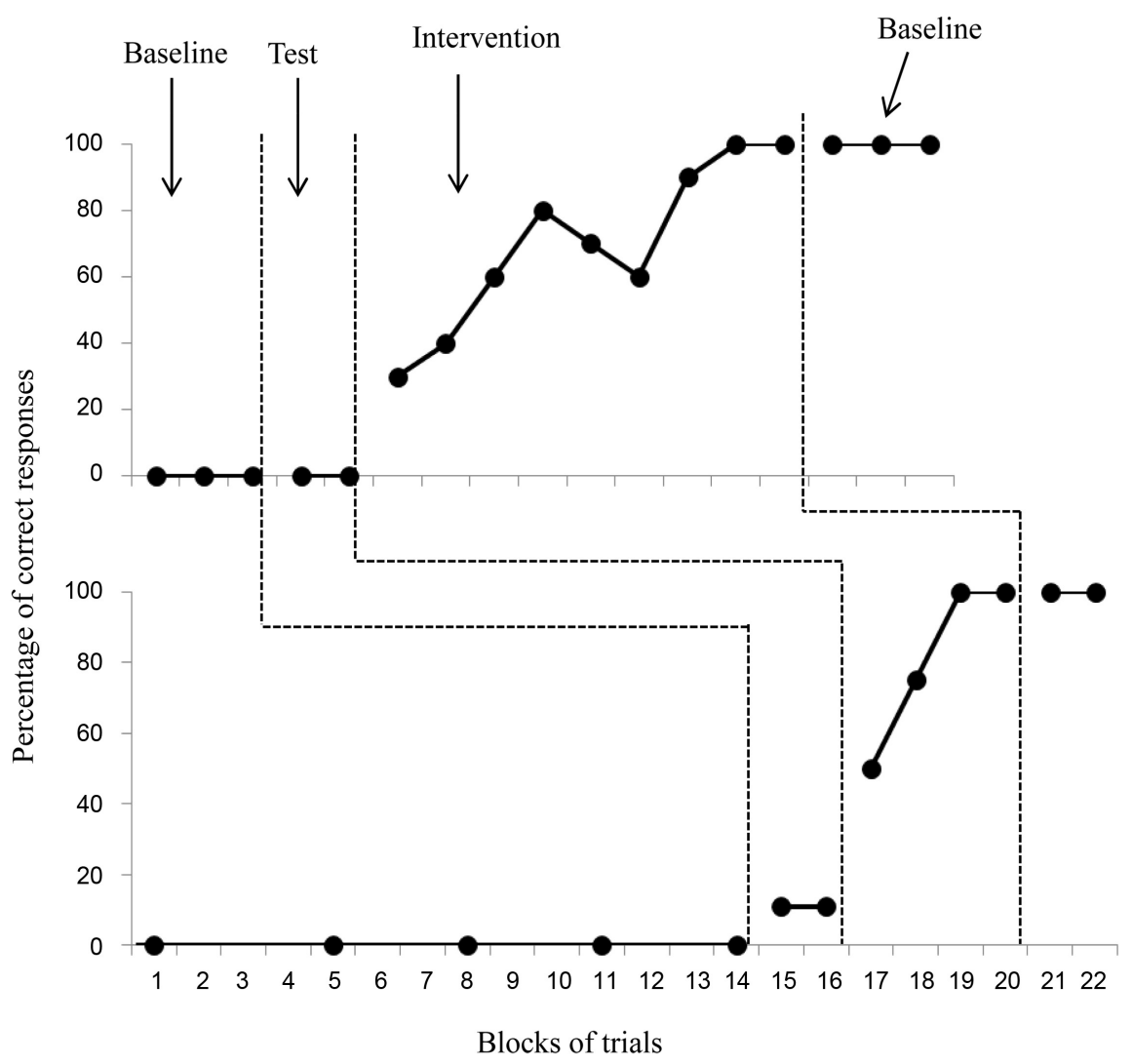

Figure 3. Percentage of steps completed correctly per block of trials for P2. Panels 1 and 2 represent data for the first (Mr. Potato Head) and second (hamburger) toy sets.

only. 11 and nine blocks, respectively, were necessary for the establishment of correct performance and without the need for intervention. It appears that training of first and second sets influenced performance on the remaining ones. Figure 3 shows the same kind of data for P2.

Figure 3 shows that, for $\mathrm{P} 2$ with whom procedures were programmed with only two toy sets, the data from the first baseline assessment indicated no correct performance in three consecutive blocks of trials for the first toy set. The instruction test condition showed no correct performance in two consecutive blocks. During intervention condition, nine blocks of trials were necessary to establish $100 \%$ correct responses and the condition was terminated. The return to baseline condition with the pictures in new order showed emergent performance free from errors in three consecutive blocks. For the second toy set, baseline level of responding involved no correct response across several blocks and performance in two consecutive blocks during the instruction test condition was near zero. The programing of intervention condition demanded four blocks to reach criteria. When baseline condition was reinstated with the pictures in a new order, correct performance was maintained in two consecutive blocks of trials. Figure 4 depicts data for the last participant, P3.

According to Figure 4, P3 demonstrated a near zero performance in the first block and zero correct performance for the remaining two blocks of trials during 


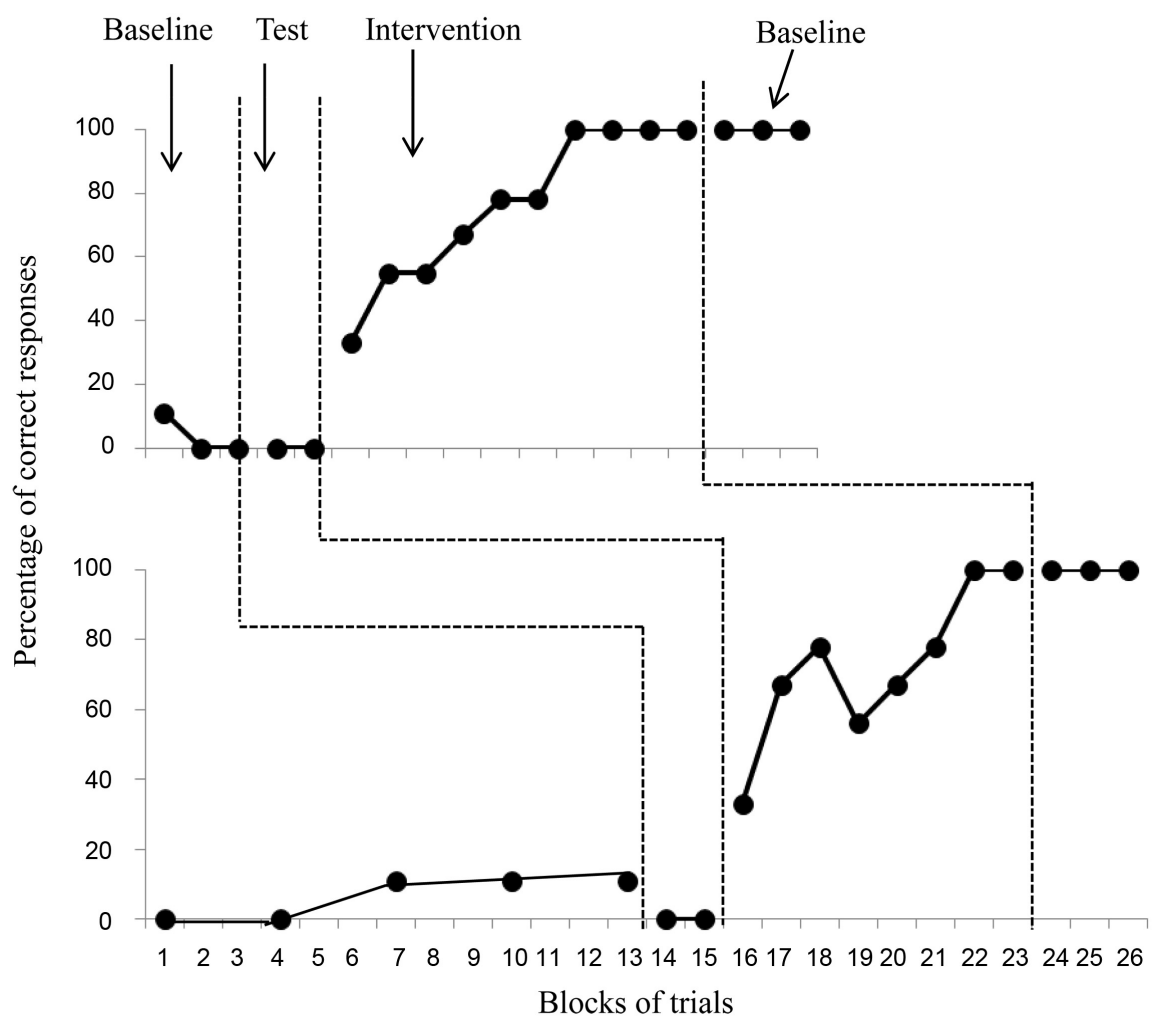

Figure 4. Percentage of steps completed correctly per block of trials for P3. Panels 1 and 2 represent data for the first (Mr. Potato Head) and second (hamburger) toy sets.

the first baseline for the first toy set and no correct responses were verified during the instruction test condition. Eight blocks of trials were necessary to establish the criteria of $100 \%$ correct responses in two consecutive blocks of trials, although the participant was exposed during two more blocks. After baseline condition was reinstated with the pictures in new order, correct responding was maintained free from errors in three consecutive blocks. For the second toy set, performance during the first baseline also involved none or almost no correct responses. There was no correct responding during the instruction test condition as well. During intervention, eight blocks were needed to reach criteria. Finally, a performance free from errors was also maintained for three consecutive blocks in the second baseline condition with the pictures in new order.

\section{Discussion}

The current study replicated the data from the previous one (Phillips \& Vollmer, 2012) in the sense that the intervention condition successfully established correct performance for all participants and toy sets to which it was applied. They all reached criteria, which was defined as a function of errorless two consecutive blocks of trials at least. P1 only needed six and eight blocks for the first and second toy sets, respectively. Training was not necessary for third and fourth toy sets, considering that data showed that, after training proved to be successful for the first and second sets, an increase to $100 \%$ correct responses was seen for the 
remaining ones, suggesting that it was a measure of generalization, replicating part of the data from the previous research mentioned. The establishment of clear and precise commands and criteria seem to favor the symbolic capacity of playing in children with autism, which is impaired in many of them, and justifies the capacity for generalization. The impaired play skills in these children may cause strangeness to their interlocutors in the school context, for example, who are confused about how to respond to build a shared sense with each other in the interaction, leading to possible relational gaps (Martins, 2009; Martins \& Monteiro, 2017; Matos, Matos, \& Figueredo, 2017).

The generalization effect was not demonstrated by P2 and P3 to whom only two toy sets were used due to the unavailability of more sets for these children. This was a limitation of the study and should be addressed by research in the future. The intervention also proved to be effective regardless and only nine and four blocks were needed in first and second set, respectively, for P2. P3 needed eight blocks in both first and second toy sets. Perhaps a similar generalization effect would be demonstrated if P2 and P3 were exposed to more toy sets like P1.

The performance on third and fourth toy sets for P1 also served to demonstrate response control by the pictorial stimuli. The same seems to be true considering the data depicted during the second baseline after training with all participants. Second baseline assessed control by the pictorial stimuli with the manipulation of the pictures portraying the first and second toy sets for all participants in a new order. $100 \%$ correct responses were established in two or three blocks of trials. Overall, data extended the previous research suggesting that intervention produced stimulus control by the pictures.

Maintenance and generalization to new environments were not directly assessed nevertheless, and this was a limitation of the current study. Future researches should address this issue by adding a follow up condition and testing generalization to new contexts, such as the school. Further investigation on the theme may be useful to legitimate new methodologies and technologies of teaching, which may improve important skills for the development of children with ASD. Among them, functional and symbolic play skills are relevant for the later establishment of social skills, regarding specially the relationship among different children, which frequently involves play. Evidence based-practices should be incorporated in several contexts in which children with ASD are inserted and the school is an environment, which evokes play behaviors and interaction among peers through play. Professionals such as school psychologists should become knowledgeable of evidence based-practices such as those described in researches like the current one and guide parents and teachers. In this direction, Otero et al. (2017) affirm that the school psychologists are required to work with teachers and parents to provide them with necessary strategies to help children function better at school, home and other environments. Thus, interventions at school based on advancements from scientific research should be conducted by psychologists in the process of expanding inclusion practices for children with autism (Akers et al., 2016; Nunes \& Santos, 2015; Martins \& Mon- 
teiro, 2017; Phillips \& Vollmer, 2012).

Overall, the procedures from the current study proved to be effective for all participants in a manner similar to what happened in the research by Phillips and Vollmer (2012). In fact, as it was mentioned before, the children from this study had no previous experience with photographic activity schedules in school contexts, which was different from the previous research case. Anyway, data indicated that the procedures were effective in establishing functional play behaviors in three children with developmental delays (two of them with ASD) in another country (Brazil) with differences in culture when compared to United States. The play skills consisting in performing sequences of behaviors with the toys and parts from different sets were successfully established for all three participants, as well as the pictures portraying play behaviors from the binder possibly became critical controlling variables of the behaviors, considering that probes conducted with the pictures arranged in a new order showed that the participants demonstrated all behaviors portrayed in the pictures and under their control. This outcome may have implications for the process of inclusion of these children in contexts such as school, which is a place where many skills should be acquired. Functional play may be considered one pre-requisite for the later development of social skills, which are important for the interaction with peers. Play is part of this process among children and, in school, agents such as the teachers should encourage the development of many skills, including those important for appropriate relationships. School psychologists, who advocate the use of evidence-based practices derived from psychological science, may assist the educators in the process of inclusion of children with ASD and other cases of learning disabilities. The procedures from this and previous studies, which only represent one possibility of intervention concerning one specific type of repertoire, are examples of procedures, which may help children with ASD to become more functional in life.

The amelioration of deficits in play skills represents one of the major concerns for the interventionist, considering that they are key components to the development of verbal behavior (Skinner, 1957/1978). However, it is known that many children with autism do not show interest in toys and, if play is supposed to be fun, uninterested children are more likely to show lack in spontaneity. In this sense, one can assume that teaching chains of play behaviors through activity schedule may fail in producing gains beyond the learning of chains addressed by the intervention. However, one may also assume that investing in a good rapport (the establishment of the experimenters as conditioned reinforcers) with the children is important to expand interests and learning may become more natural, and generalizable to educational contexts, which favors the inclusion process. The establishment of toys and leisure activities as strong motivators (conditioned reinforcers) is critical for the promotion of more natural learning. The researches on activity schedule are committed to this goal, although each child is so unique and poses challenges that may demand adaptations by experimenters and interventionists in the search for the best possible outcomes. 
Still regarding verbal behavior, it is important to mention that two of the participants (P1 and P3) demonstrated several examples of vocal verbal operants such as mands and tacts. During some sessions, they occasionally tacted the toys and some of their parts (ex: "The nose! The hat!"), and emitted mands to a specific toy (ex: "I want hamburger!"). They sometimes emitted these verbal operants establishing eye contact with the experimenter, and one may assume it represents joint attention. The most interesting fact is that no contingencies were programmed for these skills and their demonstration was quite spontaneous. This outcome seems to suggest that the toys and the experimenter herself became conditioned reinforcers, thus increasing the establishment of spontaneous verbal behavior. P1 was the non-autistic child and used to be very sensitive to social stimuli provided by adults and $\mathrm{P}$, although autistic was also very sensitive to the same kind of stimuli and this may have facilitated, for both children, the development of independent verbal behavior as a byproduct of the programmed contingencies to establish functional play skills. Nevertheless, P2, who was the child who lacked joint attention skills the most and did not seem to care much about social stimuli in the form of verbal praise and other kinds of differential attention, never showed spontaneous verbal behavior and joint attention. This specific participant did not show any clear behavior, which could indicate, that the toys and the experimenter had not been established as conditioned reinforcers. The parents also reported that the child never showed interest for toys like those used in the present research after data collection was terminated. It is important to say that none of these data were collected systematically, which represents another methodological limitation of this study and future ones should address this issue. Anyway, all the information provided so far suggests that the establishment of a good relationship with the experimenter and the toys as strong motivators is critical to produce gains beyond the learning of the play repertoires addressed by this kind of research.

\section{Final Considerations}

Given the focus on inclusive education in Brazil where students with autism are being taught in regular schools, school psychologists are invited to work with interventions based on scientific data and to support the expansion of educational strategies that have been shown to be effective for these students. Due to the different educational needs of children and young people with autism, these professionals may need to call upon the knowledge and experience from many areas of clinical practice.

This study sought to demonstrate the effectiveness of structured interventions for the expansion of functional play behaviors. The promising results are related to three central factors: firstly, the adoption of psychographic protocols in an environment of structured intervention, which evidences adequate empirical foundations; moreover, the research design with emphasis on one-to-one relationship allows for the continuous recording of participants' responses and their 
monitoring throughout the course of the planned intervention; finally, the importance of the generalization of functional play behaviors to other naturalistic environments is reiterated, and school is a privileged space for the maintenance and even the expansion of appropriate and important behaviors for the acquisition of proper skills to school education.

\section{Conflicts of Interest}

The authors declare no conflicts of interest regarding the publication of this paper.

\section{References}

Akers, J. S., Higbee, T. S., Pollard, J. S., Pellegrino, A. J., \& Gerencser, K. R. (2016). An Evaluation of Photographic Activity Schedules to Increase Independent Playground Skills in Young Children with Autism. Journal of Applied Behavior Analysis, 49, 954-959. https://doi.org/10.1002/jaba.327

Brazil (1996). Lei de Diretrizes e Bases da Educação Nacional. [The Work of Psychologists in Non-Governmental Organizations in the Educational Field.] Lei $\mathrm{n}^{\circ}$ 9.394, de 20 de dezembro de 1996

Brazil (2008). Política Nacional de Educação Especial na Perspectiva da Educação Inclusiva. [The National Policy of Special Education on the Perspective of Inclusive Education.] Brasília: MEC/SEESP.

Brazil (2012). Política Nacional de Proteção dos Direitos das Pessoas com Transtorno do Espectro do Autismo. [National Policy on the Protection of the Rights of Persons with Autism Spectrum Disorder.] Brasília: MEC/SEESP.

Brazil (2015). Lei Brasileira de Inclusão da Pessoa com Deficiência. [Brazilian Law on the Inclusion of Persons with Disabilities.] Lei no 13.146, de 6 de julho de 2015. http://legislacao.planalto.gov.br/legisla/legislacao.nsf/Viw_Identificacao/lei\%2013.1462015?OpenDocument

Dazzani, M. V. (2010). A Psicologia Escolar e a Educação Inclusiva: Uma leitura crítica. [School Psychology and Inclusive Education: A Critical Reading.] Psicologia Ciência e Profissão, 30, 362-375. https://doi.org/10.1590/S1414-98932010000200011

Galvão, P. G. \& Beckman, M. V. R. (2016). A Educação Inclusiva no Contexto da Política Nacional da Educação Especial: Atuação e Compromisso da Psicologia Escolar. [Inclusive Education in the Context of the National Policy of Special Education: Performance and Commitment of School Psychology.] In D. C. Matos (Ed.), Análise do Comportamento Aplicada ao Desenvolvimento Atípico com Ênfase em Autismo (pp. 199-226). Porto Velho: AICSA.

Gomes, C., \& Souza, V. L. T. (2011). Educação, psicologia escolar e inclusão: Aproximações necessárias. [Education, School Psychology and Inclusion: Approaches Needed.] Revista Psicopedagogia, 28, 185-193. http://pepsic.bvsalud.org/pdf/psicoped/v28n86/09.pdf

Horner, R. D., \& Baer, D.M. (1978). Multiple-Probe Technique: A Variation of the Multiple Baseline. Journal of Applied Behavior Analysis, 11, 189-196. https://doi.org/10.1901/jaba.1978.11-189

Kasari, C., Chang, Y. C., \& Patterson, S. (2013). Pretending to Play or Playing to Pretend. Autism Speaks, 6, 124-135.

http://www.journalofplay.org/sites/www.journalofplay.org/files/pdf-articles/6-1-article -pretending-to-play.pdf 
Lemos, E. L. M. D., Salomão, H. H., Braz-Aquino, F. S. \& Agripino-Ramos, C. S. (2016). Concepções de pais e professores sobre a inclusão de crianças autistas. [Parents and Teachers Conceptions about the Inclusion of Autistic Children.] Fractal: Revista de Psicologia, 28, 351-361.

Martins, A. D. F. (2009). Crianças autistas em situação de brincadeira: Apontamentos para as práticas educativas (Dissertação de mestrado não publicada). [Autistic Children in Play Situation: Notes for Educational Practices.] Piracicaba, SP: Universidade Metodista de Piracicaba.

Martins, A. D. F. \& Monteiro, M. I. B. (2017). Alunos autistas: Análise das possibilidades de interação social no contexto pedagógico. [Autistic Students: Analysis of the Possibilities of Social Interaction in the Pedagogical Context.] Psicologia Escolar e Educacional, 21, 215-224. https://doi.org/10.1590/2175-3539201702121108

Matos, D. C., \& Matos, P. G. S. (2017). Assessment, Intervention and Consulting in School Psychology in Children with Autismo: LAPITEA Laboratory in Brazil. Psychology, 8, 1774-1801. https://doi.org/10.4236/psych.2017.811117

Matos, D. C., Matos, P. G. S., \& Figueiredo, R. M. E. (2017). Teaching Intraverbal Storytelling to Children with Autism and Other Cases of Language Delays. Psychology, 8, 798-814. https://doi.org/10.4236/psych.2017.86051

Nunes, D. R. P., \& Santos, L. B. (2015). Merging Practices in Alternative Communication: An Autism Case Study. Psicologia Escolar e Educacional, 19, 59-69. https://doi.org/10.1590/2175-3539/2015/0191797

Orrú, S. E. (2006). The Constitution of the Language of Autistic Students Supported in Alternative Supplementary Communication. Piracicaba: Universidade Metodista de Piracicaba.

Otero, T. M., Fina, C., Barker, L., \& Skues, J. (2017). Evidence-Based Assessment and Intervention for Autism in School Psychology. In M. Thielking, \& M. D. Terjesen (Eds.), Handbook of Australian School Psychology (pp. 377-396). Berlin: Springer. https://doi.org/10.1007/978-3-319-45166-4_19

Partington, J. W. (2006). The Assessment of Basic Language and Learning Skills. Pleasant Hill, CA: Behavior Analysts Inc.

Passerino, L. M., \& Santarosa, L. C. (2007). Social Interaction in Austim in Learning Virtual Environment. Psicologia: Reflexão e crítica, 20, 54-64. https://doi.org/10.1590/S0102-79722007000100008

Pierce, K. L., \& Schreibman, L. (1994). Teaching Daily Living Skills to Children with Autismo in Unsupervised Settings through Pictorial Self-Management. Journal of Applied Behavior Analysis, 27, 471-481. https://doi.org/10.1901/jaba.1994.27-471

Phillips, C. L., \& Vollmer, T. R. (2012). Generalized Instruction Following with Pictorial Prompts. Journal of Applied Behavior Analysis, 45, 37-54.

https://doi.org/10.1901/jaba.2012.45-37

Sanini, C., Sifuentes, M., \& Bosa, C. A. (2013). Social Competence and Autism: The Role of the Context of Play with Peers. Psicologia: Teoria e Pesquisa, 29, 99-105. https://doi.org/10.1590/S0102-37722013000100012

Skinner, B. F. (2003). Science and Human Behavior. Trabalho original publicado em 1953, São Paulo: Edart.

Skinner, B. F. (1978). O comportamento verbal. Publicação original 1957, São Paulo: Cultrix.

Skinner, B. F. (1972). Technology of Teaching (R. Azzi, Trad.). Tradução da edição original de 1968, São Paulo: E.P.U. 
Stichter, J. P., Riley Tillman, C., \& Jimerson, S. R. (2016). Assessing, Understanding, and Supporting Students with Autism at School: Contemporary Science, Practice, and Policy. School Psychology Quarterly, 31, 443-449. https://doi.org/10.1037/spq0000184

Sundberg, M. L. (2008). The Verbal Behavior Milestones Assessment and Placement Program: The VB-MAPP(2nd ed.). Concord, CA: AVB Press.

Wacker, D. P., \& Berg, W. K. (1983). Effects of Picture Prompts on the Acquisition of Complex Vocational Tasks by Mentally Retarded Adolescents. Journal of Applied Behavior Analysis, 16, 417-433. https://doi.org/10.1901/jaba.1983.16-417

Wacker, D. P., Berg, W. K., Berrie, P., \& Swatta, P. (1985). Gneralization and Maintenance of Complex Skills by Severely Handicapped Adolescents Following Picture Prompt Training. Journal of Applied Behavior Analysis, 18, 329-336.

https://doi.org/10.1901/jaba.1985.18-329

Wong, C., \& Kasari, C. (2012). Play and Joint Attention of Children with Autism in the Preschool Special Education Classroom. Journal of Autism and Developmental Disorders, 42, 2152-2161. https://doi.org/10.1007/s10803-012-1467-2 